\title{
A Comparative Study of Toxigenic and Non-toxigenic Strains of Aspergillus flavus
}

\author{
BY S. R. GUPTA, L. VISWANATHAN \\ AND T. A. VENKITASUBRAMANIAN \\ Department of Biochemistry, Vallabhbhai Patel Chest Institute, \\ University of Delhi, Delhi-7, India \\ (Accepted for publication 23 December 1970)
}

SUMMARY

The formation of kojic acid and aflatoxins by a toxigenic and a non-toxigenic strain of Aspergillus flavus was investigated using still and shake cultures on a glucose salts medium (AM medium) and a sucrose yeast extract medium (YES medium). YES medium supported better growth of both the strains and still cultures on this medium yielded the largest levels of kojic acid with both the strains. With the toxigenic strain, still cultures on this medium also produced the maximum amount of aflatoxins. The ratio of aflatoxins $B$ to $G$ and the ratio of aflatoxins in the mycelium to those in the medium were very low in YES medium still cultures. The significance of these data is discussed.

\section{IN TRODUCTION}

Aspergillus flavus is known to invade agricultural products and produce a group of toxic metabolites known as aflatoxins (Wogan, I966). Although several studies have been carried out on A. flavus with reference to aflatoxins (Hesseltine, Shotwell, Ellis \& Stubblefield, I966; Basappa, Sreenwasamurthy \& Parpia, 1970; Hesseltine, Sorenson \& Smith, 1970), a comparative study of toxigenic and non-toxigenic strains has not been reported. Such a study is here described.

\section{METHODS}

Aspergillus flacus strains ATCC I55I 7 and ATCC 9643, which are toxigenic and nontoxigenic respectively, were obtained from the Northern Regional Research Laboratory, Peoria, Illinois, U.S.A. Spores from I week cultures on a glucose + peptone agar medium were transferred to $100 \mathrm{ml}$. of liquid medium contained in $500 \mathrm{ml}$. Erlenmeyer flasks. The fungus was grown at $25^{\circ}$ in stationary culture or on a rotary shaker. A $5.0 \%$ glucose + salts medium (AM medium) (Adye \& Mateles, 1964) and a $20.0 \%$ sucrose $+2.0 \%$ yeast extract medium (YES medium) (Davis, Diener \& Eldridge, 1966) were used. All treatments were in triplicate; the average values are presented here.

Kojic acid was estimated by the method of Parrish, Wiley, Simmons \& Long (1966). Mycelium and medium were separately extracted with chloroform, and the aflatoxins in the extract were separated by thin-layer chromatography on silica gel G with $2 \%$ methanol in chloroform. They were eluted with methanol and estimated by spectrophotometry as described by Nabney \& Nesbitt (1965). 


\section{RESULTS AND DISCUSSION}

Higher mycelial weights were obtained on YES medium, especially in shake cultures (Table I). The increase in mycelial weight continued throughout the experimental period, whereas mycelial weight reached a maximum on 4 th to 6 th day on AM medium. This difference may have been at least in part due to the higher content of carbohydrate in YES medium.

Kojic acid yield ranged from $133 \mathrm{mg}$. to $3.4 \mathrm{~g}$. depending upon the medium and the strain used. The amount of kojic acid in the medium generally continued to increase with age of the culture (Table 2), but whereas still cultures on YES medium gave very large yields of the order of $2 \cdot 7$ to $3.4 \mathrm{~g}$./flask, shake cultures in the same medium produced negligible amounts of kojic acid. Still cultures on AM medium revealed a

Table I. Growth of toxigenic and non-toxigenic strains of Aspergillus flavus in still and shake culture in AM and YES media

\begin{tabular}{|c|c|c|c|c|}
\hline \multirow{3}{*}{$\begin{array}{l}\text { Days of } \\
\text { growth }\end{array}$} & \multicolumn{4}{|c|}{ Wet weight of the mycelium (g./flask) } \\
\hline & \multicolumn{2}{|c|}{ AM medium } & \multicolumn{2}{|c|}{ YES Medium } \\
\hline & Still culture & Shake culture & Still culture & Shake culture \\
\hline \multicolumn{5}{|c|}{ Toxigenic strain ATCC 15517} \\
\hline $\mathbf{I}$ & * & $*$ & $*$ & $4 \cdot 7 \mathrm{I}$ \\
\hline 2 & $*$ & 0.69 & * & $6 \cdot 12$ \\
\hline 3 & $*$ & 3.01 & * & $7 \cdot 22$ \\
\hline 4 & $3 \cdot 19$ & 3.52 & $2 \cdot 59$ & $9 \cdot 23$ \\
\hline 6 & 3.09 & $2 \cdot 85$ & $3 \cdot 70$ & $x 1-67$ \\
\hline 8 & $2 \cdot 84$ & $2 \cdot 52$ & $4 \cdot 35$ & $12 \cdot 40$ \\
\hline I I & $2 \cdot 59$ & $2 \cdot 78$ & $5 \cdot 25$ & $12 \cdot 90$ \\
\hline 14 & $2 \cdot 46$ & $*$ & $6 \cdot 5 \mathrm{I}$ & $*$ \\
\hline \multicolumn{5}{|c|}{ Non-toxigenic strain ATCC 9643} \\
\hline I & $*$ & $*$ & * & $4 \cdot 15$ \\
\hline 2 & $3 \cdot 14$ & 0.56 & $*$ & 4.92 \\
\hline 3 & $*$ & 2.91 & $*$ & 8.05 \\
\hline 4 & 3.83 & $2 \cdot 59$ & $2 \cdot 74$ & $8 \cdot 60$ \\
\hline 6 & 3.71 & 2.04 & 4.59 & 10.39 \\
\hline 8 & 3.49 & $2 \cdot 33$ & $5 \cdot 15$ & 10.80 \\
\hline I I & $2 \cdot 96$ & $2 \cdot 55$ & 7.05 & I I $\cdot 83$ \\
\hline I4 & $2 \cdot 76$ & * & $8 \cdot 29$ & * \\
\hline
\end{tabular}

remarkable difference between the two strains, the toxigenic strain yielding a maximum of $133 \mathrm{mg}$. of kojic acid and the non-toxigenic I.05 g. Heathcote, Child \& Dutton (1965) have suggested that kojic acid is a precursor of aflatoxins. Tulpule (I969) has put forward a similar view, based on incorporation studies using $\left[{ }^{4} \mathrm{C}\right]$ kojic acid and on the finding that, on a glucose-salts medium, a toxigenic strain formed more kojic acid than a non-toxigenic strain. However, in the present study, the toxigenic strain formed less kojic acid than did the non-toxigenic strain in a glucose-salts medium. Kojic acid has been shown to be formed directly from $\left[{ }^{4} \mathrm{C}\right] \mathrm{glucose}$ (Arnstein \& Bentley, 1953), whereas aflatoxins are formed from $\left[{ }^{14} \mathrm{C}\right]$ acetate (Adye \& Mateles, I964). It therefore appears that kojic acid may not be a precursor of aflatoxins, although conditions of growth and media required for efficient production of aflatoxins and kojic acid are very similar. 
Total aflatoxins increased throughout the experimental period in still cultures on YES medium (Table 3). The maximum yields were $6.4 \mathrm{mg}$./flask compared to only $258 \mu \mathrm{g}$. in AM medium. This is in agreement with the findings of Davis et al. (1966). In both media, still cultures gave higher yields than shake cultures, though the differences in AM medium were not so marked as in YES medium. Aflatoxin levels reached a maximum after 4 to 6 days depending upon the medium, and thereafter decreased, except in YES medium still culture. This is in agreement with the findings of other workers (Ciegler, Peterson, Logoda \& Hall, I966; Schroeder, I966).

Table 2. Production of kojic acid by toxigenic and non-toxigenic strains of Aspergillus flavus in still and shake culture in AM and YES media

\begin{tabular}{|c|c|c|c|c|}
\hline \multirow{3}{*}{$\begin{array}{l}\text { Days of } \\
\text { growth }\end{array}$} & \multicolumn{4}{|c|}{ Kojic acid (mg./flask) } \\
\hline & \multicolumn{2}{|c|}{ AM medium } & \multicolumn{2}{|c|}{ YES medium } \\
\hline & Still culture & Shake culture & Still culture & Shake culture \\
\hline \multicolumn{5}{|c|}{ Toxigenic strain ATCC 15517} \\
\hline I & * & * & * & Nil \\
\hline 2 & * & Nil & * & Nil \\
\hline 3 & * & Nil & * & $32 \cdot 0$ \\
\hline 4 & Nil & Nil & $155^{\circ} 0$ & $43 \cdot 7$ \\
\hline 6 & 13.4 & 137.5 & $504 \cdot 0$ & $91 \cdot 9$ \\
\hline 8 & $28 \cdot 5$ & 628.8 & I396.8 & I 17.7 \\
\hline II & 107.5 & $780 \cdot 0$ & $2560 \cdot 0$ & $224 \cdot 2$ \\
\hline 14 & I33.I & * & $3376 \cdot 0$ & * \\
\hline \multicolumn{5}{|c|}{ Non-toxigenic strain ATCC 9643} \\
\hline I & * & * & * & Nil \\
\hline 2 & $307 \cdot 0$ & Nil & * & Nil \\
\hline 3 & $*$ & Nil & * & $15 \cdot 7$ \\
\hline 4 & $440 \cdot 4$ & Nil & $620 \cdot 0$ & $36 \cdot 4$ \\
\hline 6 & $435 \cdot 3$ & $130 \cdot 6$ & $1550 \cdot 0$ & $108 \cdot i$ \\
\hline 8 & $1050 \cdot 0$ & $320 \cdot 6$ & $2522 \cdot 0$ & $131 \cdot 7$ \\
\hline II & $92 \mathrm{I} \cdot 7$ & $507 \cdot 9$ & $2677 \cdot 0$ & $185^{\circ} 0$ \\
\hline 14 & $69 r \cdot 3$ & & $2677^{\circ} 0$ & * \\
\hline
\end{tabular}

Ciegler et al. (I966) studied the degradation of aflatoxins in submerged cultures and showed that increased aeration increased their breakdown. This would explain the low levels obtained in YES medium in shake cultures as compared to still cultures. Aflatoxin $G$ was present in only traces in mycelia grown in shake cultures apparently because it was degraded more.

The ratio of aflatoxins $B$ to $G$ was dependent on the medium. It was low in still cultures in YES medium. In still cultures in AM medium the ratio was much greater in the mycelium than in the medium. The reverse was true in still cultures in YES medium. It appears that the proportion of aflatoxin $\mathrm{G}$ was higher when large amounts of aflatoxin were produced. This view is supported by the data of Schroeder (1966) and Schindler, Palmer \& Eisenberg (1967).

In still cultures in YES medium, the ratio of aflatoxins in the mycelium to those in the medium was very low and of the order of 0.07 to 0.1 . Under all the other conditions employed, the ratio was comparatively high and ranged from 0.35 to $\mathrm{I} \cdot 84$. The relative amounts of aflatoxins present in the medium and mycelium have been reported to 


\section{S. R. GUPTA, L. VISWANATHAN AND T. A. VENKITASUBRAMANIAN}

vary with the media and growth conditions (Schroeder \& Ashworth, I966; Frank, I968). These workers' data also showed a decrease in the ratio of aflatoxins in the mycelium to those in the medium when aflatoxin production was high. Since aflatoxin

Table 3. Production of aflatoxins $B$ and $G$ by a toxigenic strain of Aspergillus flavus in still and shake culture in AM and YES media

\begin{tabular}{|c|c|c|c|c|c|c|c|c|c|c|}
\hline \multirow{4}{*}{$\begin{array}{l}\text { Days of } \\
\text { growth }\end{array}$} & \multicolumn{9}{|c|}{ Aflatoxin ( $\mu$ g./flask) } & \\
\hline & \multicolumn{5}{|c|}{ AM medium } & \multicolumn{5}{|c|}{ YES medium } \\
\hline & \multicolumn{2}{|c|}{ Mycelium } & \multicolumn{2}{|c|}{ Medium } & \multirow[b]{2}{*}{ Total } & \multicolumn{2}{|c|}{ Mycelium } & \multicolumn{2}{|c|}{ Medium } & \multirow[b]{2}{*}{ Total } \\
\hline & B & G & B & $\mathbf{G}$ & & $\mathrm{B}$ & G & B & $\mathbf{G}$ & \\
\hline \multicolumn{11}{|c|}{ Still culture } \\
\hline 4 & $34 \cdot 6$ & $8 \cdot 5$ & $42 \cdot 7$ & $65 \cdot 9$ & $15 I \cdot 7$ & I $5 \cdot I$ & 130.6 & $462 \cdot 0$ & $1225^{\circ} 0$ & $1832 \cdot 7$ \\
\hline 6 & $64 \cdot 2$ & 19.2 & $102 \cdot 0$ & $72 \cdot 4$ & $257 \cdot 8$ & $28 \cdot 3$ & $235 \cdot 8$ & $826 \cdot 0$ & $1837^{\circ} 0$ & $2927 \cdot \mathrm{I}$ \\
\hline 8 & $37 \cdot 1$ & $7 \cdot 3$ & $52 \cdot 0$ & $4 I \cdot 8$ & $138 \cdot 2$ & $43 \cdot 8$ & $234 \cdot 7$ & $1386 \cdot 0$ & 1960.0 & $3624 \cdot 5$ \\
\hline II & $22 \cdot 4$ & $4 \cdot 7$ & $40 \cdot 3$ & 33.8 & $\mathrm{IOI} \cdot 2$ & $65 \cdot 5$ & $376 \cdot 9$ & $2971 \cdot 0$ & 3307.0 & 6420.4 \\
\hline 14 & $16 \cdot 0$ & $20 \cdot 0$ & $29 \cdot 3$ & $16 \cdot 9$ & $82 \cdot 2$ & $5 I \cdot I$ & $45 \cdot 5$ & $2846 \cdot 0$ & $3430 \cdot 0$ & $6372 \cdot 6$ \\
\hline \multicolumn{11}{|c|}{ Shake culture } \\
\hline I & * & * & * & $*$ & $*$ & Trace & Trace & $16 \cdot 4$ & $16 \cdot 4$ & $32 \cdot 8$ \\
\hline 2 & Trace & Trace & 14.8 & 16.0 & $30 \cdot 8$ & Trace & Trace & $28 \cdot 6$ & $20 \cdot 3$ & $49 \cdot 2$ \\
\hline 3 & $24 \cdot 9$ & Trace & $46 \cdot 5$ & $22 \cdot 8$ & $94 \cdot 2$ & $4 \cdot 0$ & Trace & $26 \cdot 5$ & $2 \mathrm{I} \cdot 2$ & $5 I \cdot 7$ \\
\hline 4 & $52 \cdot 3$ & Trace & $30 \cdot 7$ & $20 \cdot 5$ & 103.5 & $39 \cdot 9$ & Trace & $45^{\cdot 2}$ & $28 \cdot 9$ & I 14.0 \\
\hline 6 & $60 \cdot 8$ & $22 \cdot 31$ & $23 \cdot 6$ & $21 \cdot 9$ & $128 \cdot 6$ & $84 \cdot 2$ & Trace & $37 \cdot 3$ & $22 \cdot 7$ & $144^{\circ} 2$ \\
\hline 8 & $20 \cdot I$ & Trace & $19 \cdot 2$ & $17 \cdot 4$ & $56 \cdot 7$ & $34 \cdot 6$ & Trace & $24 \cdot 9$ & $11 \cdot 6$ & $7 \mathrm{I} \cdot \mathrm{I}$ \\
\hline I I & $28 \cdot I$ & Trace & $20 \cdot 3$ & Trace & $48 \cdot 4$ & $153 \cdot 7$ & Trace & $81 \cdot 1$ & $8 \mathrm{I} \cdot \mathrm{I}$ & 315.9 \\
\hline
\end{tabular}

appears to be excreted with ease into the medium, large amounts of toxins can be expected to accumulate in the medium over a period of time. Apparently there is a limit to the amount of toxins that can be held in the mycelium and hence mycelium: medium ratio is very low when toxin formation is high.

One of the authors (S. R. G.) is grateful to the Directorate General of Health Services, Government of India, for a Research Scholarship. The work was supported in part by PL-480 Grant no. FG-In-259.

\section{REFERENCES}

ADYE, J. \& MATELES, R. I. (I964). Incorporation of labelled compounds into aflatoxins. Biochimica et biophysica acta 86, 418-420.

Arnstein, H. R. V. \& Bentley, R. (1953). Biosynthesis of kojic acid. I. Production from [1-C $\left.{ }^{14}\right]-$ and $\left[3,4-C^{14}\right]$-glucose and [2-C'14]-I,3-di-hydroxyacetone. Biochemical Journal 54, 493-508.

Basappa, S. C., Sreenwasamurthy, V. \& Parpia, H. A. B. (I970). Aflatoxin and kojic acid production by resting cells of Aspergillus flavus Link. Journal of General Microbiology 6r, 8I-86.

Ciegler, A., Peterson, R. E., Logoda, A. A. \& Hall, H. H. (1966). Aflatoxin production and degradation by Aspergillus flavus in 20 litre fermentors. Applied Microbiology 14, 826-833.

Davis, N. D., Diener, U. L. \& Eldridge, D. W. (I966). Production of aflatoxin $B_{1}$ and $G_{1}$ by Aspergillus flavus in a semisynthetic medium. Applied Microbiology 14, 378-380.

FRANK, H. K. (1968). Diffusion of aflatoxins in foodstuffs. Journal of Food Science 33, 98-100.

Heathcote, J. G., Child, J. J. \& Dutton, N. F. (1965). The possible role of kojic acid in the production of aflatoxin by Aspergillus flavus. Biochemical Journal 95, $23 \mathrm{p}$. 
Hesseltine, C. W., Shotwell, O. L., Ellis, J. J. \& Stubblefield, R. D. (I966). Aflatoxin formation by Aspergillus flavus. Bacteriological Reviews 30, 795-805.

Hesseltine, C. W., Sorenson, W. G. \& SMith, M. (1970). Taxonomic studies of the aflatoxinproducing strains in the Aspergillus flavus group. Mycologia 62, I23-I32.

NABney, J. \& NesbitT, B. F. (1965). A spectrophotometric method for determining the aflatoxins. Analyst 90, 155-I60.

Parrish, F. W., Wiley, B. J., Simmons, E. G. \& Long, L., Jun. (1966). Production of aflatoxin and kojic acid by species of Aspergillus flavus and Penicillium. Applied Microbiology r4, I39.

Schindler, A. F., Palmer, J. G. \& Eisenberg, W. B. (1967). Aflatoxin production by Aspergillus flavus as related to various temperatures. Applied Microbiology r5, 1006-1009.

SCHROEDER, H. W. (1966). Effect of corn steep liquor on mycelial growth and aflatoxin production in Aspergillus parasiticus. Applied Microbiology 14, 38I-385.

Schroeder, H. W. \& Ashworth, L. J., Jun. (1966). Aflatoxins: Some factors affecting production and location of toxins in Aspergillus flavus-oryzae. Journal of Stored Products Research 1, 267-271.

Tulpule, P. G. (1969). Aflatoxicosis. Indian Journal of Medical Research 57, I02-I I4.

Wogan, G. N. (1966). Chemical nature and biological effects of the aflatoxins. Bacteriological Reviews 30, 460-470. 